\title{
Multiple adaptive routes of Salmonella enterica Typhimurium to biocide and antibiotic exposure
}

Tânia Curiao ${ }^{1,2^{*}}$, Emmanuela Marchi ${ }^{4}$, Denis Grandgirard ${ }^{5}$, Ricardo León-Sampedro ${ }^{1,2}$, Carlo Viti ${ }^{4}$, Stephen L. Leib ${ }^{5}$, Fernando Baquero ${ }^{1,2,3}$, Marco R. Oggioni ${ }^{6}$, José Luis Martinez ${ }^{3,7}$ and Teresa M. Coque ${ }^{1,2,3^{*}}$

\begin{abstract}
Background: Biocides and antibiotics are used to eradicate or prevent the growth of microbial species on surfaces (occasionally on catheters), or infected sites, either in combination or sequentially, raising concerns about the development of co-resistance to both antimicrobial types. The effect of such compounds on Salmonella enterica, a major food-borne and zoonotic pathogen, has been analysed in different studies, but only few works evaluated its biological cost, and the overall effects at the genomic and transcriptomic levels associated with diverse phenotypes resulting from biocide exposure, which was the aim of this work.

Results: Exposure to triclosan, clorhexidine, benzalkonium, (but not to hypochlorite) resulted in mutants with different phenotypes to a wide range of antimicrobials even unrelated to the selective agent. Most biocide-resistant mutants showed increased susceptibility to compounds acting on the cell wall ( $\beta$-lactams) or the cell membranes (poly-L-lysine, polymyxin B, colistin or toxic anions). Mutations (SNPs) were found in three intergenic regions and nine genes, which have a role in energy production, amino acids, carbohydrates or lipids metabolism, some of them involved in membrane transport and pathogenicity. Comparative transcriptomics of biocide-resistant mutants showed over-expression of genes encoding efflux pumps (sugE), ribosomal and transcription-related proteins, cold-shock response (среE) and enzymes of microaerobic metabolism including those of the phosphotransferase system. Mainly ribosomal, metabolic and pathogenicity-related genes had affected expression in both in vitro-selected biocide mutants and field Salmonella isolates with reduced biocide susceptibility.
\end{abstract}

Conclusions: Multiple pathways can be involved in the adaptation of Salmonella to biocides, mainly related with global stress, or involving metabolic and membrane alterations, and eventually causing "collateral sensitivity" to other antimicrobials. These changes might impact the bacterial-environment interaction, imposing significant bacterial fitness costs which may reduce the chances of fixation and spread of biocide resistant mutants.

Keywords: Biocide resistance, Antimicrobial susceptibility, WGS, Transcriptomics, Collateral sensitivity

\section{Background}

Salmonella enterica is a major food-borne pathogen able to cause diarrhoea or thyphoid/paratyphoid fever [1]. The systemic infection is often preceded by an asymptomatic chronic colonization or by a local infection process. One of the major problems associated with persistent colonization or infection is the steady rise of

\footnotetext{
*Correspondence: taniacuri@gmail.com; teresacoque@gmail.com 'Servicio de Microbiología, Instituto Ramón y Cajal de Investigación Sanitaria (IRYCIS), Madrid, Spain

Full list of author information is available at the end of the article
}

antibiotic resistance among strains, which can lead to treatment failures [2]. The association between the overuse of antibiotics and/or biocides in farms, hospitals, industry and homes and the emergence of both coresistance and cross-resistance to different compounds in Salmonella populations is of concern [3-6].

Unlike antibiotics, most biocides do not act on specific cell targets. In fact, only a few mechanisms by which microorganisms became tolerant to these antimicrobials have been fully characterized. Over-expression of multidrug efflux pumps such as AcrAB or AcrEF which are 
controlled by global transcriptional regulators such as MarAB, RamA and SoxRS can lead to diverse levels of resistance to biocides and/or antibiotics [7-13]. Often, tolerance to triclosan is due to over-expression and/or mutations in FabI, the enoyl-acyl-reductase protein required for fatty acid synthesis [14]. Moreover, exposure and further adaptation to biocides may also impair cellular homeostasis, and/or changes the level of expression of genes regulating synthesis and modification of cell envelope, virulence, motility, or stress response [15-20]. Whether or not such physiological changes are needed for adaptation to the presence of biocides, or they just reflect secondary changes associated with restoring fitness after adaptation remains to be established. Previous studies in Salmonella enterica prototype strain SL1344 have described the modification of antibiotic susceptibility, growth and regulation of different genes after exposure to biocides [5, 6, 21]. However, few studies provided comprehensive information about the genomic and transcriptomic changes of mutants selected after exposure to different biocides and antibiotics, which can be used either coincidentally or sequentially in the clinical practice and in the food industry $[9,22-24]$.

The aim of this study was to determine the effect of exposure to some biocides (triclosan, TRI; benzalkonium chloride, BKC; chlorhexidine, CHX and sodium hypochlorite, SHC), or antibiotics (ampicillin, AMP; ciprofloxacin, CIP), widely used in farms, hospitals, industry and homes on the selection of antibiotic/biocide- resistant Salmonella mutants and to characterize the associated genomic and transcriptomic profiles, as well as the extended phenotypes (susceptibility to 240 inhibitory compounds). To address whether these adaptive changes found in laboratory-selected mutants also occurred in natural populations of Salmonella, the transcriptomes of a set of field isolates exhibiting reduced susceptibility to biocides were comparatively studied.

\section{Methods}

\section{Bacterial strains}

The prototype S. enterica serovar Typhimurium SL1344 [25] strain was exposed to biocides (TRI, CHX, BKC and SHC), and antibiotics (the $\beta$-lactam ampicillin, AMP; and the fluoroquinolone ciprofloxacin, CIP). The quantitative phenotype of this strain against diverse antimicrobials is summarized in Table 1.

Sixteen Salmonella spp. isolates from food-borne animals with reduced susceptibility to TRI ( $3 \mathrm{TRI}^{\mathrm{R}}$; MIC 1$2 \mathrm{mg} / \mathrm{L}$ ), BKC (7 BKC ${ }^{\mathrm{R}}$; MIC = $128 \mathrm{mg} / \mathrm{L}$ ), CHX (1 being $\mathrm{CHX}^{\mathrm{R}} / \mathrm{BKC}^{\mathrm{R}}, \mathrm{MIC}=16 \mathrm{mg} / \mathrm{L}$ (Additional file 1: Figure S1) used in a previous work [26], were investigated for their transcriptomic profiles. Such isolates, collected in a veterinary surveillance project in Europe, showed 13 different PFGE-types and belonged to Salmonella enterica subspecies enterica [serovars Anatum $(\mathrm{n}=8)$, Hadar $(\mathrm{n}=$ 5), Dublin ( $\mathrm{n}=2)$ ] and subspecies Typhimurium $(\mathrm{n}=1)$.

Most of these strains were susceptible to antibiotics. A few number of isolates harbored plasmids that contained

Table 1 Susceptibility profiles of Salmonella mutants respect to SL1344 parental strain

\begin{tabular}{|c|c|c|c|c|c|c|c|c|c|c|c|c|c|c|c|}
\hline \multirow[t]{2}{*}{$\bar{N} .^{\circ}$} & \multirow{2}{*}{$\begin{array}{l}\text { Pre-conditioning } \\
\text { agent }\end{array}$} & \multirow[t]{2}{*}{ Biocide Phenotype } & \multicolumn{3}{|c|}{ Biocide MIC (mg/L) } & \multicolumn{7}{|c|}{ Antibiotic MIC (mg/L) } & \multirow{2}{*}{$\begin{array}{l}\text { Mutant } \\
\text { designation }\end{array}$} & \multirow{2}{*}{$\begin{array}{l}\text { Fitness } \\
\text { Cost (\%) }\end{array}$} & \multirow{2}{*}{$\begin{array}{l}\text { Frequency } \\
\text { of mutation }\end{array}$} \\
\hline & & & $\mathrm{TRI}$ & BKC & $\mathrm{CHX}$ & AMP & CAZ & CIP & ERY & GEN & $\mathrm{CLO}$ & $\overline{\mathrm{TET}}$ & & & \\
\hline & - & Parental strain SL1344 & 0.06 & 16 & 16 & 1.5 & 0.38 & 0.032 & 32 & 1.0 & 3 & 3 & & & \\
\hline 1 & NE & $\mathrm{TRI}^{\mathrm{R}} / \mathrm{BKC}^{\mathrm{R}} / \mathrm{CH} \mathrm{X}^{\mathrm{R}}$ & 2 & 32 & 32 & 1.5 & 0.38 & 0.047 & $32-48$ & 1.5 & 3 & 2 & NE/TRI1 & 11 & $>1.25 \mathrm{E}-07$ \\
\hline 2 & NE & & 0.12 & 32 & 32 & 1 & 0.25 & 0.032 & 32 & 1.0 & 4 & 4 & $\underline{\mathrm{NE} / \mathrm{CH} X 2}$ & 34 & 2.92E-09 \\
\hline 3 & $\mathrm{BKC}$ & & 0.12 & 32 & 32 & 2 & 0.38 & 0.023 & 32 & 1.5 & 3 & 4 & BKC/AMP & - & 2.50E-09 \\
\hline 4 & $\mathrm{CHX}$ & & 0.12 & 32 & 32 & 1 & 0.5 & 0.032 & 48 & 1.5 & 2 & 2 & $\mathrm{CHX/BKC3}$ & - & 1.67E-09 \\
\hline 5 & $\mathrm{BKC}$ & $\mathrm{TRl}^{\mathrm{R}} / \mathrm{BKC}^{\mathrm{R}}$ & 0.12 & 32 & 16 & 2 & 0.38 & 0.032 & 48 & 0.5 & 4 & 4 & $\mathrm{BKC} / \mathrm{BKC} 3$ & - & 2.50E-09 \\
\hline 6 & CIP & $B K C^{R}$ & 0.06 & 32 & 16 & 1.5 & 0.5 & 0.032 & 24 & 1.5 & $2-3$ & 1.5 & CIP/TRI1 & More fit & $<1.50 \mathrm{E}-05$ \\
\hline 7 & $\mathrm{TRI}$ & & 0.06 & 32 & 16 & 2 & 0.5 & 0.032 & 32 & 1.5 & 3 & $2-3$ & $\underline{\mathrm{TRI} / \mathrm{BKC} 3}$ & 31 & 1.50E-09 \\
\hline 8 & NE & $\mathrm{BKC}^{\mathrm{R}} / \mathrm{CHX} \mathrm{X}^{\mathrm{R}} / \mathrm{TRI}{ }^{\mathrm{HS}}$ & 0.03 & 32 & 32 & 2 & 0.38 & 0.032 & $32-48$ & 1 & 4 & 4 & NE/BKC2 & - & $1.25 \mathrm{E}-07$ \\
\hline 9 & $\mathrm{NE}$ & & 0.03 & 32 & 32 & 1.5 & 0.75 & 0.047 & 24 & 1.5 & 3 & 1.5 & $\underline{\mathrm{NE} / \mathrm{BKC} 3}$ & more fit & $2.08 \mathrm{E}-11$ \\
\hline 10 & $\mathrm{TRI}$ & & 0.015 & 32 & 32 & 1.5 & 0.5 & 0.032 & 24 & 1.5 & 2 & 1.5 & TRI/AMP & - & 3.06E-09 \\
\hline 11 & $B K C$ & & 0.015 & 64 & 32 & 2 & 0.38 & 0.023 & 32 & 1 & 3 & 4 & $\mathrm{BKC/CHX2}$ & - & 1.67E-08 \\
\hline 12 & CIP & $\mathrm{TRI}^{\mathrm{HS}} / \mathrm{CHX}{ }^{\mathrm{HS}}$ & 0.03 & 16 & 8 & 2 & 0.38 & 0.032 & 32 & 2 & 4 & 3 & $\mathrm{CIP} / \mathrm{CHX} 1$ & - & $<2.50 \mathrm{E}-06$ \\
\hline 13 & $\mathrm{BKC}$ & $\mathrm{TRI}^{\mathrm{HS}}$ & 0.015 & 16 & 16 & 1 & 0.38 & 0.023 & 64 & 1.5 & 3 & 1.5 & $\mathrm{BKC/CIP}$ & - & 1.50E-09 \\
\hline 14 & $\mathrm{CHX}$ & & 0.015 & 16 & 16 & 2 & 0.38 & 0.023 & $32-48$ & 0.75 & 3 & 4 & $\mathrm{CHX} / \mathrm{AMP}$ & 17 & 4.17E-09 \\
\hline
\end{tabular}

NE: non-exposed, - Not done

In the designation of mutants, numbers 1-3 refer to the concentration of compounds in plates as follows: $1-32 \mathrm{mg} / \mathrm{L}, 2-64 \mathrm{mg} / \mathrm{L}$ and 3-128 mg/L Mutants CIP/TRI1 and CIP/CHX1 classified as more fit than SL1344 exhibited $-17 \%$ and $-21 \%$, respectively

WGS was performed in the underlined mutants 
acquired genes coding for resistance to $\beta$-lactams (bla $a_{\text {TEM- }}$ $\left.{ }_{1}\right)$, aminoglycosides $(\operatorname{str} A, \operatorname{str} B)$, tetracycline $(\operatorname{tet} A$, tet $R)$ and quinolone (qepA). Plasmids from 6 isolates also carried genes encoding resistance to metals (As, Co).

\section{Selection of mutants}

A colony of S. enterica serovar Typhimurium SL1344 grown overnight in Luria Bertani (LB) plates was inoculated into LB-broth and LB supplemented with subinhibitory concentrations $(1 / 2 \times \mathrm{MIC})$ of biocides (TRI, CHX, BKC and SHC; Sigma-Aldrich, Inc., St. Louis, MO) or antibiotics (AMP and CIP) and further incubated overnight at $37{ }^{\circ} \mathrm{C}$ with shaking at $150 \mathrm{rpm}$. Subsequently, aliquots of $100 \mu \mathrm{l}$ were plated onto LB plates containing a single biocide or a single antibiotic compound at concentrations ranging 2.5-33 $\times$ MIC and incubated at $30{ }^{\circ} \mathrm{C}$. These primary selective plates were examined for growth during 7 days. A variable number of viable mutants (one per colony morphotype per plate) were tested for growth on secondary selective plates containing other biocides or antibiotics. The stability of mutants was evaluated after serial passages in nonselective LB broth (up to 50 generations). Mutants were named by the acronym name of the antimicrobial compound added to the broth cultures before plating, followed by the name and concentration of the compound added to the selective agar plates from where the mutant was retrieved. The mutants obtained from broth cultures not supplemented with any antimicrobial were designated as non-exposed (NE). Phenotypes of decreased and increased susceptibility to biocides and antibiotics appear represented by the super indexes " $R$ " or "HS", respectively. The colonial morphology in LB and blood agar plates was compared between mutants and the parental strain. The variability of $\mathrm{XbaI}$-digested genomic DNA profiles of mutants and parental strain was assessed by pulsed field gel electrophoresis (PFGE) using standard protocols for DNA preparation, digestion and PFGE running conditions for Enterobacteriaceae [27].

\section{Antimicrobial susceptibility testing}

The minimal inhibitory concentrations (MICs) of biocides (TRI, CHX, BKC) and antibiotics (AMP; CAZ; CIP; erythromycin, ERY; gentamicin, GEN; chloramphenicol, CLO; tetracycline, TET) (BioMérieux, Marcy l'Etoile, France) were determined by both broth microdilution using E- test strips following CLSI guidelines. Escherichia coli ATCC10536 and Staphylococcus aureus ATCC6538 were used as control strains (3). Minimum bactericidal concentrations (MBCs) were determined by subculturing $10 \mu \mathrm{l}$ from each well without visible bacterial growth when MIC was determined on MuellerHinton broth (Difco, Becton Dickinson, Maryland, USA). The minimal concentration yielding no-growth after overnight incubation at $37{ }^{\circ} \mathrm{C}$ was scored as the $\mathrm{MBC}$. The susceptibility of wild type strains to AMP, streptomycin, sulphonamides, trimethoprim, nalidixic acid, CIP, CLO, TET, GEN and kanamycin was determined by disk diffusion.

Further, the susceptibility of mutants and the parental strain to 240 cell growth-inhibiting chemical compounds was screened using the Phenotype MicroArray PM11PM20 in two independent experiments (Biolog, Hayward, CA, USA) as previously described [28]. The strains were grown overnight at $30^{\circ} \mathrm{C}$ on BUG agar (Biolog Universal Agar, Biolog Hayward California) and then, colonies were picked up with a sterile cotton swab and suspended in $15 \mathrm{ml}$ of $1 \mathrm{X}$ inoculation fluid (IF-0a GN/GP Base, Biolog 74268). Cell density was adjusted to $85 \%$ transmittance $(\mathrm{T})$ on a Biolog turbidimeter. Inoculation fluid for PM11-20 was prepared mixing $100 \mathrm{ml}$ of IF-10a GN Base (1.2X) (Biolog 74264), $1.2 \mathrm{ml}$ of Biolog Redox Dye A (100X) (Biolog 74221), $0.6 \mathrm{ml}$ of cell suspension at $85 \% \mathrm{~T}$, bringing to a final volume of $120 \mathrm{ml}$ with sterile water. The mixture was inoculated in the PM plates (100 $\mu \mathrm{l}$ per well) and monitored automatically for color development every $15 \mathrm{~min}$ for $72 \mathrm{~h}$ at $30{ }^{\circ} \mathrm{C}$ in an Omnilog reader (Biolog). To identify phenotypes, the kinetic curves of both parental strain and mutants were compared using Omnilog-PM software (release OM_PM_109M). Such comparison was based on the half maximal inhibitory concentration (IC50) values for 4 concentrations of each antimicrobial, which is defined as the well at which a particular per-well parameter is the half of its maximal value over the concentration series; the reference parameter being the area under the curve. Raw data were filtered using differences of average area of mutant compared to control taking a difference of 1:3 (33\%) as significant.

\section{Growth kinetics}

The growth kinetics of both the parental strain SL1344 and biocide-tolerant mutants exhibiting various phenotypes was determined by measuring the optical density at $600 \mathrm{~nm}$ every $5-10 \mathrm{~min}$ for $24 \mathrm{~h}$ at $37^{\circ} \mathrm{C}$ in Bioscreen $\mathrm{C}$ (ThermoLabsystems, Helsinki, Finland), adapting the method described by Foucault et al. [29]. Inocula in a concentration of $10^{4}$ to $10^{5} \mathrm{CFU} / \mathrm{ml}$ were obtained from a 1/1000 dilution of an overnight culture in fresh LB broth and aliquots of $400 \mu \mathrm{l}$ were seeded in triplicate in a microtitre plate. Growth rates were determined in the interval estimated to be exponential using the GrowthRates 2.1 program [30]. The fitness cost (FC) reflects the relative growth rates, which were based on the individual growth rates of mutants relative to the parental strain. For each strain, data from growth rates were averaged and standard deviations calculated. 


\section{Whole genome sequencing (WGS)}

Six mutants with different phenotypes were selected for whole genome sequencing. Genomic DNA was extracted from $1 \mathrm{ml}$ of overnight cultures in plain LB broth using a Promega Wizard Genomic DNA Purification kit according manufacturer instructions. Genome sequencing was performed on Illumina MiSeq platform to obtain 100-200 bp paired-end reads. Reads were revised and corrected using Lighter software and further mapped against the genome of the SL1344 strain (GenBank acc. Number FQ312003) using Breseq v0.26.1 pipeline (http://barricklab.org/twiki/bin/view/Lab/ToolsBacterialGenomeResequencing). Single nucleotide polymorphisms (SNPs) detected in all mutants were not deemed confident and were excluded, because we cannot dismiss differences between the laboratory SL1344 strain used as wild-type in this work, and that corresponding to the canonical sequence in the GenBank database. Reads not found in all mutants were treated as deletions.

\section{Transcriptome analysis}

\section{Array Design and Production}

An array was designed to cover the complete genome of Salmonella enterica subsp. enterica serovar Typhimurium, as well as plasmids isolated from various Gramnegative microorganisms. Probe design was performed by the CustomArray Design Service (CustomArray Inc., Bothell, WA, USA) and included 12,005 capture probes (35-40 bp length), 326 quality control probes and 65 non-specific probes derived from plants, phages and unrelated bacterial sequences, and also 148 empty spots with no oligonucleotides. Arrays were synthesized on a CustomArray Synthesizer (CombiMatrix, Mukilteo, WA) and quality tested using the standard protocols provided by the manufacturer.

\section{RNA extraction}

Strains were grown overnight in $10 \mathrm{ml} \mathrm{LB}$ broth at $37^{\circ}$ $\mathrm{C}, 150 \mathrm{rpm}$. The cultures were diluted 1:100 in prewarmed LB and grown to logarithmic phase $\left(\mathrm{OD}_{570}=\right.$ 0.5). $2 \mathrm{ml}$ of the culture $\left(5 \times 10^{8}-1 \times 10^{9}\right.$ colony forming units (UFC)/ml) were harvested in $4 \mathrm{ml}$ of RNA protect reagent ${ }^{\circ}$ (Qiagen $\mathrm{GmbH}$, Hilden, Germany), incubated for $5 \mathrm{~min}$ at room temperature and centrifuged for $10 \mathrm{~min}$ at $5000 \mathrm{x}$ g. Bacterial pellets were suspended in $200 \mu \mathrm{l}$ of TE buffer $(10 \mathrm{mM}$ Tris/ $\mathrm{HCl}, 1 \mathrm{mM}$ EDTA, pH 8) containing $1 \mathrm{mg} / \mathrm{ml}$ lysozyme (Sigma) and incubated for $5 \mathrm{~min}$ at room temperature, $600 \mathrm{rpm}$. Total RNA was then extracted using RNeasy Mini Kit (Qiagen), according to the manufacturer's instructions. Contaminating DNA was removed using DNA-free ${ }^{\text {Tx }}$ Kit (Applied Biosystems). The RNA isolation procedure was validated for RNA quality by testing RNA samples on an Agilent 2100 Bioanalyzer (Agilent Technologies). RNA concentration and purity were determined by Nanodrop ${ }^{\circ}$ ND-1000 spectrophotometer (Thermo Scientific). For each strain, at least 4 RNA samples were prepared from independent cultures.

\section{RNA labelling and fragmentation}

Isolated, unamplified RNA was labelled with Cy5, using ULS $^{\mathrm{Tn}}$ Labeling Kit for CombiMatrix arrays (Kreatech Biotechnology), according to the manufacturer's instructions. RNA was fragmented with the RNA Fragmentation Reagents (Ambion ${ }^{\circ}$.

\section{Array hybridization}

$12 \mathrm{~K}$ Custom arrays were hybridized with $2 \mu \mathrm{g}$ of labelled, fragmented RNA, according to information provided by the manufacturer (Customarray/Combimatrix Incorporated). In brief, after pre-hybridization of the arrays, hybridization was performed at $45{ }^{\circ} \mathrm{C}$ for 16 hours in a hybridization buffer containing $25 \%$ formamide. After washing steps, microarrays were scanned using Packard ScanArray4000 array scanner and software (ScanArray, version 3.1, Packard BioChip Technologies) with incremental laser power from 15 to $100 \%$. Data were extracted with Microarray Imager software (version 5.8.0, Combi Matrix) and spot intensity expressed as median intensity. After scanning, microarrays were striped using $12 \mathrm{~K}$ CustomArray ${ }^{\text {ma }}$ Stripping kit, according to the manufacturer's instructions. Quality of the stripping was verified by scanning the microarray at maximal laser intensity and repeated when necessary. Microarrays were used up to four times.

\section{Data analysis}

To adjust for difference in the amount and labelling efficiency of hybridized RNAs, the median fluorescence intensity values of all spots was determined for all laser intensities used during scanning. Scanning data with similar median fluorescence intensity were chosen for further analysis. Fluorescence values of spots with maximal intensity (signal saturation) at a given laser intensity were extrapolated by linear regression, using values gathered with lower laser intensity. For each set of arrays for a given strain, non-specific binding was determined from fluorescence values of the non-specific probes. The cut-off for specific binding was set as the upper $95 \%$ confidence interval of the mean signal intensity of the non-specific probes. Probes were excluded when the mean values for the strains compared were under the cut-off value.

The fluorescence values were $\log _{2}$ transformed and stage-wise quantitative normalization was performed for each set of comparison, using a script written in the statistical computing environment of $\mathrm{R}$ ( $\mathrm{R}$ Development Core Team, 2011, version 3.3). To identify genes differentially 
regulated, we analyzed the transformed and normalized intensities determined by two methods, the Significance Analysis of Microarrays method (SAM, version 5.0, running under Shiny, a web-based interactive application framework for $\mathrm{R}$ environment, https://github.com/MikeJSeo/SAM) and "R", comprising base package statistics and the attached LIMMA package (version 3.26.5). The presence of genes identified by both methods in the mutants analyzed was searched in the wild type strains included in the study and transcriptomic profiles were compared. The expression profiles of these genes were visualized in a heatmap built with the 'pheatmap' package in " $R$ ".

\section{Statistical analysis}

In the SAM method, the delta value was set to obtain an average. False Discovery Rate (FDR) of $5 \%$ and the fold change cut-off value was established as 1.5. In LIMMA analysis, genes with a fold change $>1.5$ and $p<0.05$ were considered as differentially expressed. Only the genes identified as differentially expressed by both SAM and LIMMA were considered.

\section{Availability of supporting data}

The data sets supporting the results of this article are available in the ArrayExpress repository, (http://www.ebi.ac.uk/arrayexpress/) under accession numbers AMEXP-2366 (S. Typhimurium combimatrix $12 \mathrm{~K}$ customarray design) and E-MTAB-2554 (microarray raw results).

\section{Results}

Exposure to biocides or antibiotics yield mutants with different susceptibility to biocides and antimicrobials

Table 1 shows the diversity of mutants exhibiting phenotypes obtained $\left(4 \mathrm{TRI}^{\mathrm{R}} / \mathrm{BKC}^{\mathrm{R}} / \mathrm{CHX}{ }^{\mathrm{R}}, 1 \mathrm{TRI}^{\mathrm{R}} / \mathrm{BKC}^{\mathrm{R}}, 4\right.$ $\mathrm{BKC}^{\mathrm{R}} / \mathrm{CHX}^{\mathrm{R}} / \mathrm{TRI}^{\mathrm{HS}}, 2 \mathrm{BKC}^{\mathrm{R}}, 2 \mathrm{TRI}^{\mathrm{HS}}$ and $1 \mathrm{TRI}^{\mathrm{HS}} /$ $\mathrm{CHX}^{\mathrm{HS}}$ ). Some mutants with increased MICs to biocides were obtained without previous exposure to any antimicrobial but using selective plates supplemented with TRI, BKC or CHX. Others were retrieved after exposure to antibiotics such as CIP and AMP. Previous exposure to SHC did not yield resistant mutants. A number of biocide tolerant mutants mentioned above showed lower MIC values for AMP, CAZ, CIP, ERY, GEN, CLO and TET than those for the corresponding parental strain $(\leq 2$-fold).

Preexposure to sub-inhibitory concentrations of BKC resulted in mutants with either decreased susceptibility to $\mathrm{BKC}$, TRI and/or $\mathrm{CHX}\left(\mathrm{TRI}^{\mathrm{R}} / \mathrm{BKC}^{\mathrm{R}} / \mathrm{CHX}^{\mathrm{R}}, \mathrm{TRI}^{\mathrm{R}}\right.$ / $\mathrm{BKC}^{\mathrm{R}}$ ) or increased susceptibility to TRI (TRI ${ }^{\mathrm{HS}}, \mathrm{BKC}^{\mathrm{R}}$ / $\mathrm{CHX}^{\mathrm{R}} / \mathrm{TRI}^{\mathrm{HS}}$ ). Two of these four mutants selected in plates supplemented with $\mathrm{BKC}$ also showed a slight increase in $\mathrm{MIC}_{\mathrm{CAZ}}\left(1 \mathrm{BKC}^{\mathrm{R}}\right.$ and $\left.1 \mathrm{BKC}^{\mathrm{R}} / \mathrm{CHX}^{\mathrm{R}} / \mathrm{TRI}^{\mathrm{HS}}\right)$. The $\mathrm{TRI}^{\mathrm{R}} / \mathrm{BKC}^{\mathrm{R}} / \mathrm{CHX}{ }^{\mathrm{R}}$ and the $\mathrm{TRI}^{\mathrm{HS}}$ phenotypes were also selected after pre-exposure to CHX, CIP or without pre-exposure to any antimicrobial. A hyper-susceptible $\mathrm{TRI}^{\mathrm{HS}}$ mutant (BKC/CIP) showed a 2 -fold increased MIC $_{\text {ERY. }}$.

Preexposure to sub-inhibitory concentrations of TRI resulted in mutants that only showed the phenotypes $\mathrm{BKC}^{\mathrm{R}}$ and $\mathrm{BKC}^{\mathrm{R}} / \mathrm{CHX}^{\mathrm{R}}$, which could even exhibit increased susceptibility to TRI. Such BKC ${ }^{\mathrm{R}}$ mutants showed a minor increase in MIC values to CAZ. Two different mutants were selected on plates supplemented with TRI, one obtained without previous exposure to antimicrobials showed an increased $\mathrm{MIC}_{\mathrm{TRI}}$ (33-fold) and small increases in $\mathrm{MIC}_{\mathrm{CI}}, \mathrm{MIC}_{\mathrm{ERY}}$ and $\mathrm{MIC}_{\mathrm{GEN}}$. The other, obtained after pre-conditioning with CIP did not show an increase in $\mathrm{MIC}_{\mathrm{TRI}}$. Pre-exposure to CIP resulted on mutants showing $\mathrm{BKC}^{\mathrm{R}}$ or $\mathrm{TRI}^{\mathrm{HS}}$ phenotypes, which were closely related with the above ones.

A more comprehensive analysis of the effects that the exposure to biocides and antimicrobials had on Salmonella strain SL1344 strain was performed by characterizing the genome and transcriptome of six mutants representing the phenotypes $\mathrm{TRI}^{\mathrm{R}} / \mathrm{BKC}^{\mathrm{R}} / \mathrm{CHX}^{\mathrm{R}}(\mathrm{CHX} /$ BKC3, NE/TRI1, NE/CHX2), BKC ${ }^{\mathrm{R}} / \mathrm{CHX}^{\mathrm{R}} / \mathrm{TRI}^{\mathrm{HS}}$ (NE/ $\mathrm{BKC} 3), \mathrm{BKC}^{\mathrm{R}}$ (TRI/BKC3), and $\mathrm{TRI}^{\mathrm{HS}}$ (CHX/AMP) (Table 2).

\section{Antimicrobial susceptibility}

We identified mutants with a given biocide phenotype and variable antibiotic susceptibility patterns but also mutants exhibiting different biocide susceptibility phenotypes and similar antimicrobial susceptibility profiles (Table 3). The activity of different compounds against seven mutants and the parental strain was evaluated considering their IC50 values. High $\mathrm{IC}_{50}$ values were observed for antibiotics that inhibit protein synthesis (e.g. neomycin and thiamphenicol), specific metabolic routes as the reduction of dihydrofolic acid to tetrahydrofolic acid, which is an essential precursor in the thymidine synthesis pathway (trimethoprim), or membrane acting

Table 2 Techniques carried out for a representative subset of mutants

\begin{tabular}{lllll}
\hline Mutant $\mathrm{n}^{\circ}$ & $\begin{array}{l}\text { Mutant } \\
\text { name }\end{array}$ & $\begin{array}{l}\text { Biolog } \\
\text { (Table 3) }\end{array}$ & $\begin{array}{l}\text { WGS } \\
\text { (Table 4) }\end{array}$ & $\begin{array}{l}\text { Gene expression } \\
\text { (Fig. 1 and Fig. 2) }\end{array}$ \\
\hline 1 & NE/TRI1 & Yes & Yes & Yes \\
2 & NE/CHX2 & No & Yes & Yes \\
4 & CHX/BKC3 & Yes & Yes & Yes \\
7 & TRI/BKC3 & Yes & Yes & Yes \\
9 & NE/BKC3 & Yes & Yes & Yes \\
10 & TRI/AMP & Yes & No & No \\
11 & BKC/CHX2 & Yes & No & No \\
14 & CHX/AMP & Yes & Yes & Yes \\
\hline
\end{tabular}

Yes and No denotes whether the technique was performed or not 
Table 3 Antimicrobial susceptibility determined by BIOLOG for Salmonella enterica mutants in comparison to the parental strain

\begin{tabular}{|c|c|c|c|c|c|c|c|c|}
\hline \multirow[b]{2}{*}{ Chemicals } & \multirow[b]{2}{*}{ Inhibitor Family } & \multicolumn{2}{|c|}{$\mathrm{TRI}^{\mathrm{R}} / \mathrm{BKC}^{\mathrm{R}} / \mathrm{CHX} \mathrm{X}^{\mathrm{R}}$} & \multirow{2}{*}{$\begin{array}{l}\mathrm{BKC}^{\mathrm{R}} \\
\mathrm{TRI} / \mathrm{BKC} 3\end{array}$} & \multicolumn{3}{|c|}{$\mathrm{BKC}^{\mathrm{R}} / \mathrm{CH} X^{\mathrm{R}} / \mathrm{TRI}^{\mathrm{HS}}$} & \multirow{2}{*}{$\begin{array}{l}\mathrm{TRI}^{\mathrm{HS}} \\
\mathrm{CHX} / \mathrm{AMP}\end{array}$} \\
\hline & & NE/TRI1 & $\mathrm{CHX/BKC3}$ & & NE/BKC3 & TRI/AMP & $\mathrm{BKC} / \mathrm{CHX} 2$ & \\
\hline \multicolumn{9}{|l|}{ ANTIBIOTICS } \\
\hline Neomycin & aminoglycosides & $\mathrm{R}$ & $\mathrm{R}$ & $\mathrm{R}$ & $\mathrm{R}$ & $\mathrm{R}$ & $\mathrm{R}$ & S \\
\hline Paromomycin & & S & S & & & S & S & \\
\hline Sisomicin & & S & $\mathrm{S}$ & $\mathrm{R}$ & $\mathrm{R}$ & S & $\mathrm{R}$ & $\mathrm{R}$ \\
\hline Chloramphenicol & amphenicols & & S & S & S & & & \\
\hline Thiamphenicol & & $\mathrm{R}$ & $\mathrm{R}$ & & $\mathrm{R}$ & $\mathrm{R}$ & & $\mathrm{R}$ \\
\hline Cefazolin & cephalosporins & & $\mathrm{R}$ & & & & & \\
\hline Ceftriaxone & & & & & $S$ & & & \\
\hline Amoxicillin & \multirow[t]{4}{*}{ lactams } & $S$ & $\mathrm{R}$ & $S$ & $S$ & S & $\mathrm{R}$ & $\mathrm{R}$ \\
\hline Aztreonam & & $S$ & & $S$ & & & & S \\
\hline Carbenicillin & & $S$ & & $S$ & & & S & \\
\hline Carbenicillin (II) & & & & & & $\mathrm{R}$ & & \\
\hline Phleomycin & DNA oxidants & & & & & & $\mathrm{R}$ & \\
\hline Cinoxacin & \multirow{7}{*}{$\begin{array}{l}\text { DNA topoisomerases } \\
\text { inhibitors }\end{array}$} & S & & $S$ & $S$ & S & S & $\mathrm{R}$ \\
\hline Ciprofloxacin & & $\mathrm{R}$ & & $\mathrm{R}$ & & & $\mathrm{R}$ & $\mathrm{R}$ \\
\hline Enoxacin & & $\mathrm{R}$ & $S$ & $S$ & $S$ & S & S & $\mathrm{R}$ \\
\hline Nalidixic acid & & $\mathrm{R}$ & S & S & $\mathrm{R}$ & S & S & $\mathrm{R}$ \\
\hline Novobiocin & & S & & & & & & \\
\hline Ofloxacin & & & $S$ & $S$ & & S & S & S \\
\hline Pipemidic acid & & $\mathrm{R}$ & & & & & & \\
\hline Hydroxyurea & folate antagonists & $\mathrm{R}$ & $\mathrm{S}$ & $\mathrm{R}$ & $S$ & $\mathrm{R}$ & $\mathrm{R}$ & S \\
\hline Trimethoprim & & $\mathrm{R}$ & $\mathrm{R}$ & & $\mathrm{R}$ & $\mathrm{R}$ & & $\mathrm{R}$ \\
\hline Troleandomycin & macrolides & & $\mathrm{R}$ & $\mathrm{R}$ & & & $\mathrm{R}$ & \\
\hline Rifampicin & RNA polymerase inhibitors & & & S & & & & \\
\hline Penimepicycline & tetracyclines & & $\mathrm{S}$ & $S$ & $S$ & $\mathrm{R}$ & $S$ & \\
\hline Tetracycline & & & & $\mathrm{S}$ & & & & \\
\hline \multicolumn{9}{|l|}{ NON-ANTIBIOTICS } \\
\hline 1-Hydroxypyridine-2-thione & chelators & & & S & $S$ & & $S$ & \\
\hline 5,7-Dichloro-8-OHquinoline & & & $S$ & $S$ & & & S & \\
\hline 5-Chloro-7-iodo-8-OHquinoline & & $S$ & $\mathrm{R}$ & $S$ & $\mathrm{R}$ & S & & S \\
\hline 8-Hydroxyquinoline & & & $\mathrm{R}$ & $\mathrm{R}$ & & & $\mathrm{R}$ & $\mathrm{R}$ \\
\hline Fusaric acid & & $S$ & & $\mathrm{~s}$ & $S$ & & $S$ & \\
\hline 2-Phenylphenol & DNA intercalators & & & & & & $\mathrm{R}$ & \\
\hline Chloroxylenol & Fungicides & & & & & $\mathrm{R}$ & & \\
\hline Patulin & & & $\mathrm{R}$ & $\mathrm{R}$ & & & $\mathrm{R}$ & R \\
\hline Colistin & Membrane active agents & $\mathrm{S}$ & $\mathrm{S}$ & $\mathrm{S}$ & $S$ & S & $S$ & $\mathrm{R}$ \\
\hline Polymyxin B & & 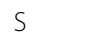 & $S$ & $S$ & $S$ & & & \\
\hline Polymyxin B (II) & & & & & & & $\mathrm{R}$ & \\
\hline Poly-L-lysine & & $S$ & $\mathrm{~S}$ & $S$ & $S$ & S & $S$ & S \\
\hline Alexidine & & $S$ & & & & & & S \\
\hline Ornidazole & oxidizing agents & $\mathrm{S}$ & & & $\mathrm{S}$ & & $S$ & \\
\hline 1-Chloro-2,4-dinitrobenzene & & $\mathrm{S}$ & $\mathrm{S}$ & $\mathrm{R}$ & $S$ & & $\mathrm{R}$ & $\mathrm{R}$ \\
\hline Atropine & other drugs & & $\mathrm{S}$ & & $\mathrm{S}$ & & & \\
\hline
\end{tabular}


Table 3 Antimicrobial susceptibility determined by BIOLOG for Salmonella enterica mutants in comparison to the parental strain (Continued)

\begin{tabular}{|c|c|c|c|c|c|c|c|c|}
\hline Pridinol & & $\mathrm{R}$ & $\mathrm{R}$ & $\mathrm{R}$ & & $\mathrm{R}$ & $\mathrm{R}$ & \\
\hline Propranolol & & & $S$ & $S$ & $S$ & $S$ & $S$ & $\mathrm{~S}$ \\
\hline Chlorpromazine & & & S & $S$ & S & $\mathrm{S}$ & $S$ & $\mathrm{~S}$ \\
\hline Benzethonium chloride & QACS & $S$ & S & $S$ & $\mathrm{R}$ & $S$ & $S$ & $\mathrm{R}$ \\
\hline Cetylpyridinium chloride & & & & & & & & $\mathrm{S}$ \\
\hline Sodium azide & respiration, uncoupler & & & $S$ & & & & \\
\hline Thioridazine & & & & $\mathrm{S}$ & S & & & $\mathrm{S}$ \\
\hline Potassium chromate & toxic anions & $S$ & $\mathrm{~S}$ & $S$ & $S$ & & $S$ & $\mathrm{R}$ \\
\hline Potassium tellurite (II) & & S & $\mathrm{R}$ & & $\mathrm{R}$ & $\mathrm{R}$ & $\mathrm{S}$ & $\mathrm{S}$ \\
\hline Sodium metaborate & & S & S & $\mathrm{S}$ & $\mathrm{S}$ & $\mathrm{S}$ & $\mathrm{S}$ & $\mathrm{S}$ \\
\hline Sodium tungstate & & & & & & $\mathrm{R}$ & & \\
\hline Sodium periodate & & & & $\mathrm{R}$ & & & $\mathrm{R}$ & \\
\hline Antimony(III) chloride & toxic cations & & $\mathrm{R}$ & $\mathrm{R}$ & $\mathrm{R}$ & $\mathrm{R}$ & & $\mathrm{R}$ \\
\hline Cadmium chloride & & $\mathrm{R}$ & & & $\mathrm{R}$ & & & \\
\hline Thallium(I) acetate & & & & $\mathrm{R}$ & & & & $\mathrm{R}$ \\
\hline D,L-Methionine hydroxamate & other inhibitors & $\mathrm{S}$ & $\mathrm{S}$ & $\mathrm{S}$ & $\mathrm{S}$ & $\mathrm{S}$ & $\mathrm{S}$ & $\mathrm{S}$ \\
\hline Phenyl-methylsulfonyl-fluoride & & S & & $S$ & S & $\mathrm{S}$ & $\mathrm{S}$ & $\mathrm{S}$ \\
\hline D-Serine & & $\mathrm{R}$ & & & & & & \\
\hline 6-Mercaptopurine & & & S & $S$ & & $\mathrm{R}$ & & \\
\hline Compound $48 / 80$ & & & & & $S$ & $\mathrm{~S}$ & & \\
\hline
\end{tabular}

Blank cells indicate that no variation in the susceptibility were found in comparison to the parental strain

compounds (toxic cations, such as antimony (III) chloride). Conversely, compounds that act on the bacterial cell envelopes (such as colistin, $\beta$-lactams, poly-L-lysine, polymyxin B), toxic anions (e.g. potassium chromate), quaternary salts (e.g. sodium metaborate) and protease inhibitors showed low $\mathrm{IC}_{50}$ values.

Within this common antimicrobial susceptibility profile, differences were observed for some mutants. The two $\mathrm{TRI}^{\mathrm{R}} / \mathrm{BKC}^{\mathrm{R}} / \mathrm{CHX}^{\mathrm{R}}$ (CHX/BKC3, NE/TRI1) and the $\mathrm{BKC}^{\mathrm{R}} / \mathrm{CHX}^{\mathrm{R}} / \mathrm{TRI}^{\mathrm{HS}}$ (NE/BKC3) exhibited an increased susceptibility to the oxidizing agent 1-chloro-2,4-dinitrobenzene, and the tRNA synthetase inhibitor D,L-methionine hydroxamate. The two mutants exhibiting decreased susceptibility to CIP by standard MIC testing, TRI ${ }^{\mathrm{R}}$ / $\mathrm{BKC}^{\mathrm{R}} / \mathrm{CHX}^{\mathrm{R}}$ (NE/TRI1) and $\mathrm{BKC}^{\mathrm{R}} / \mathrm{CHX}^{\mathrm{R}} / \mathrm{TRI}^{\mathrm{HS}}$ (NE/ $\mathrm{BKC} 3$ ) also showed resistance to other quinolones such as nalidixic acid and/or enoxacin. Those with increased susceptibility to TRI [BKC ${ }^{\mathrm{R}} / \mathrm{CHX}^{\mathrm{R}} / \mathrm{TRI}^{\mathrm{HS}}(\mathrm{NE} / \mathrm{BKC} 3)$ and $\mathrm{TRI}^{\mathrm{HS}}$ (CHX/AMP)] were more tolerant to benzethonium chloride than the parental strain. This compound is a synthetic QAC widely used in different settings, including the food industry as a hard-surface disinfectant, antiseptic, and in foaming hand sanitizers [31]. It is noteworthy that resistance to TRI in Salmonella was frequently associated with tolerance to several antibiotics of different families, with the exception of aminoglycosides.

\section{Changes in the genome of SL1344 strain after exposure to biocides}

The six SL1344 mutants fully sequenced showed SNPs and deletions in genes involved in cell division/stress, membrane transport, cell motility, metabolism and virulence (Table 4).

The three $\mathrm{TRI}^{\mathrm{R}} / \mathrm{BKC}^{\mathrm{R}} / \mathrm{CHX} \mathrm{R}^{\mathrm{R}}$ mutants (NE/TRI1, $\mathrm{CHX} / \mathrm{BKC} 3$, and NE/CHX2) differed in the number and nucleotide changes. The NE/TRI1 mutant presenting the highest $\mathrm{MIC}_{\mathrm{TRI}}$ value $(2 \mathrm{mg} / \mathrm{L})$ had a SNP in the $f a b I$ gene that resulted in the Gly93Ser change in the binding site of FabI. It also presented a SNP in the ftsK gene, which is involved in cell division and likely in the last steps of peptidoglycan biosynthesis. The CHX/BKC3 mutant harboured two mutations in the fts $K$ gene and a SNP in the yeaN gene, which encodes a still uncharacterized transporter of the Major Facilitator Superfamily (MFS). Finally, the NE/CHX2 mutant showed a SNP in the intergenic region in the boundary of $\mathrm{purH}$ and the 16S rRNA genes, the former related to purine metabolism and previously associated with virulence in different bacterial species.

The $\mathrm{BKC}^{\mathrm{R}} / \mathrm{CHX}^{\mathrm{R}} / \mathrm{TRI}^{\mathrm{HS}}$ (NE/BKC3) mutant showed unique SNPs in mipA, asnA, aarF genes, but the same SNP described above for NE/CHX2. MipA is an outer membrane protein possibly involved in a novel antibiotic 
Table 4 Mutations identified in sequenced mutants

\begin{tabular}{|c|c|c|c|c|c|c|c|}
\hline \multirow[b]{2}{*}{ Function } & \multirow[b]{2}{*}{ Gene } & \multicolumn{3}{|l|}{$\mathrm{TRI}^{\mathrm{R}} \mathrm{CH} \mathrm{X}^{\mathrm{R}} \mathrm{BKC}^{\mathrm{R}}$} & \multirow{2}{*}{$\begin{array}{l}\text { BKC }^{R} \\
\text { TRI/BKC3 }\end{array}$} & \multirow{2}{*}{$\begin{array}{l}\mathrm{TRI}^{\mathrm{HS}} \mathrm{CHX}^{\mathrm{R}} \mathrm{BKC}^{\mathrm{R}} \\
\mathrm{NE} / \mathrm{BKC} 3\end{array}$} & \multirow{2}{*}{$\begin{array}{l}\text { TRI }^{\mathrm{HS}} \\
\mathrm{CHX} / \mathrm{AMP}\end{array}$} \\
\hline & & NE/TRI1 & $\mathrm{NE} / \mathrm{CHX} 2$ & $\mathrm{CHX} / \mathrm{BKC} 3$ & & & \\
\hline $\begin{array}{l}\text { Amino acid/peptide } \\
\text { transport/metabolism }\end{array}$ & $\operatorname{asn} A^{a}$ & & & & & $\mathrm{G} \rightarrow \mathrm{T} / \mathrm{A} 74 \mathrm{~A}$ & \\
\hline $\begin{array}{l}\text { Energy production/ } \\
\text { amino acid metabolism }\end{array}$ & aarF ${ }^{b}$ & & & & & $\mathrm{~T} \rightarrow \mathrm{A} / \mathrm{L} 317 \mathrm{Q}$ & \\
\hline Lipid metabolism & $\left.f a b\right|^{c}$ & $\mathrm{G} \rightarrow \mathrm{A} / \mathrm{G} 93 \mathrm{~S}$ & & & & & \\
\hline Membrane/transport & tolA ${ }^{d}$ & & & & & & $\mathrm{~T} \rightarrow \mathrm{A} N 168 \mathrm{E}$ \\
\hline Replication & $f t s K^{e}$ & $\mathrm{~T} \rightarrow \mathrm{G} / \mathrm{P} 772 \mathrm{P}$ & & $\mathrm{A} \rightarrow \mathrm{T} / \mathrm{Q} 780 \mathrm{H} \quad \mathrm{A} \rightarrow \mathrm{T} / \mathrm{Q} 793 \mathrm{H}$ & & & \\
\hline \multirow[t]{2}{*}{ Surface structures } & $\operatorname{mip}^{f}$ & & & & & $\mathrm{~T} \rightarrow \mathrm{C} / \mathrm{F} 61 \mathrm{~L}$ & \\
\hline & $\operatorname{mot} B^{g}$ & & & & $\mathrm{~T} \rightarrow \mathrm{G} / \mathrm{E} 128 \mathrm{D}$ & & \\
\hline Virulence & bigA ${ }^{\mathrm{h}}$ & & Deletion:408 bp & & Deletion:331 bp & & Deletion:293 bp \\
\hline \multirow[t]{3}{*}{ Intergenic } & $--^{i}$ & & & & & & $\mathrm{~T} \rightarrow \mathrm{A}$ \\
\hline & purH $\mathrm{j}^{\mathrm{j}}-$ & & $A \rightarrow C$ & & & $A \rightarrow C$ & \\
\hline & tdcA/garA ${ }^{k}$ & & & & $C \rightarrow T$ & & \\
\hline Unknown & yean ${ }^{\prime}$ & & & $\mathrm{C} \rightarrow \mathrm{G} / \mathrm{T} 321 \mathrm{~T}$ & & & \\
\hline
\end{tabular}

Description of gene products: ${ }^{a}$ Asparagine synthetase $\mathrm{A},{ }^{\mathrm{b}}$ Ubiquinone biosynthesis protein; ${ }^{\mathrm{c}}$ Enoyl-acyl carrier protein reductase (NADH); ${ }^{\mathrm{d}}$ Membrane transporter TolA protein; ${ }^{\mathrm{e}}$ Cell division protein FtsK; ${ }^{\mathrm{f}}$ Hypothetical outer membrane protein; ${ }^{9}$ Motility protein $\mathrm{B} ;{ }^{\mathrm{h}}$ Hypothetical surface-exposed virulence protein; ${ }^{\mathrm{i}}$ Intergenic region between Glutamyl-t-RNA synthetase (459 bp)/(359 bp) Xanthosin operon transcriptional regulator; ${ }^{j}$ Intergenic region between Phosphoribosylaminoimidezolecarboxamide fosmyltransferase and IMP cyclohydrolase/- (16S rRNA); ${ }^{k} t d c$ operon transcriptional activator/Hypothetical surface-exposed virulence protein; ${ }^{1}$ Hypothetical membrane protein of Major Facilitator Superfamily (transporter)

resistance mechanism against kanamycin in E. coli [32]. The other genes are related to the metabolism of amino acids and ubiquinones.

The TRI ${ }^{\mathrm{HS}}$ mutant (CHX/AMP) showed an amino acid change in TolA, the membrane protein specialized in colicin uptake which has been previously involved in detergent tolerance [33], along with a mutation in the intergenic region between the glutamyl-t-RNA synthetase (459 bp)/(359 bp) and the regulator of the xanthosin operon transcriptional regulator.

The genome of the $B K C^{R}$ mutant (TRI/BKC3) showed three changes located at the nucleotide sequence of motB gene, the intergenic region next the $t d c / g a r A$ operon and a deletion in the bigA gene. The $\operatorname{mot} B$ (and mot $A$ ) gene encodes flagellar motor proteins that generate the stator and proton channel anchored to the peptidoglycan layer. The $t d c$ operon is a single transcriptional unit involved in threonine and serine metabolism during anaerobic growth. Finally, deletions in the bigA gene encoding a hypothetical surface/exposed protein were associated with virulence in some intracellular pathogens [34]. Deletions in bigA gene were also found in other two mutants showing $\mathrm{TRI}^{\mathrm{HS}}$ (CHX/AMP) and $\mathrm{TRI}^{\mathrm{R}} / \mathrm{BKC}^{\mathrm{R}} / \mathrm{CHX}^{\mathrm{R}}(\mathrm{NE} / \mathrm{CHX} 2)$ phenotypes.

\section{Changes in the transcriptome of S. enterica SL1344 biocide resistant mutants}

Figure 1 shows the Volcano Plots of genes altered after exposure to biocides in the six mutants analyzed and Fig. 2, the heatmap clustering mutants according to the expression profiles of genes identified as differently regulated using both methods (LIMMA and SAM). Down regulation of genes was more remarkable than overexpression of genes (-4 fold vs 2 fold Additional file 2: Table S1).

Differential expression was identified for genes involved in cellular metabolism (carbohydrate, lipid, amino acid, and cofactors), energy production, ion transport/metabolism, protein synthesis and signal chemotaxis pathways (Additional file 3: Table 2). The expression of genes classically involved in tolerance to biocides as efflux-pumps (tolC, sugE) was slightly increased in some mutants.

Two TRI ${ }^{\mathrm{R}} \mathrm{CHX}{ }^{\mathrm{R}} \mathrm{BKC}^{\mathrm{R}}$ mutants (CHX/BKC3, NE/TRI1) and one BKC ${ }^{\mathrm{R}}$ (TRI/BKC3) showed similar gene expression profiles. Upregulation of genes involved in protein synthesis occurred in these three mutants, and some other changes were common, either in three or two of them, involving genes related to transcription such as rpoZ and rрo $B$ which encodes subunits of the RNA polymerase. Conversely, transcriptional regulators were repressed in NE/TRI (malT) and CHX/BKC3 and TRI/BKC3 (hilC, hilD, sprB). The maltose monomeric activator MalT is a LuxR/UhpA member, a family of large size proteins believed to have another functions (e.g. amino acid metabolism). The others are members of the AraC family and negative regulators of HilA, the key regulator of the Salmonella pathogenicity island 1 (SPI1) $[35,36]$.

Both TRI/BKC3 and CHX/BKC3 mutants shared a pattern of down-regulation of genes related to transport and metabolism with a potential role in virulence such 


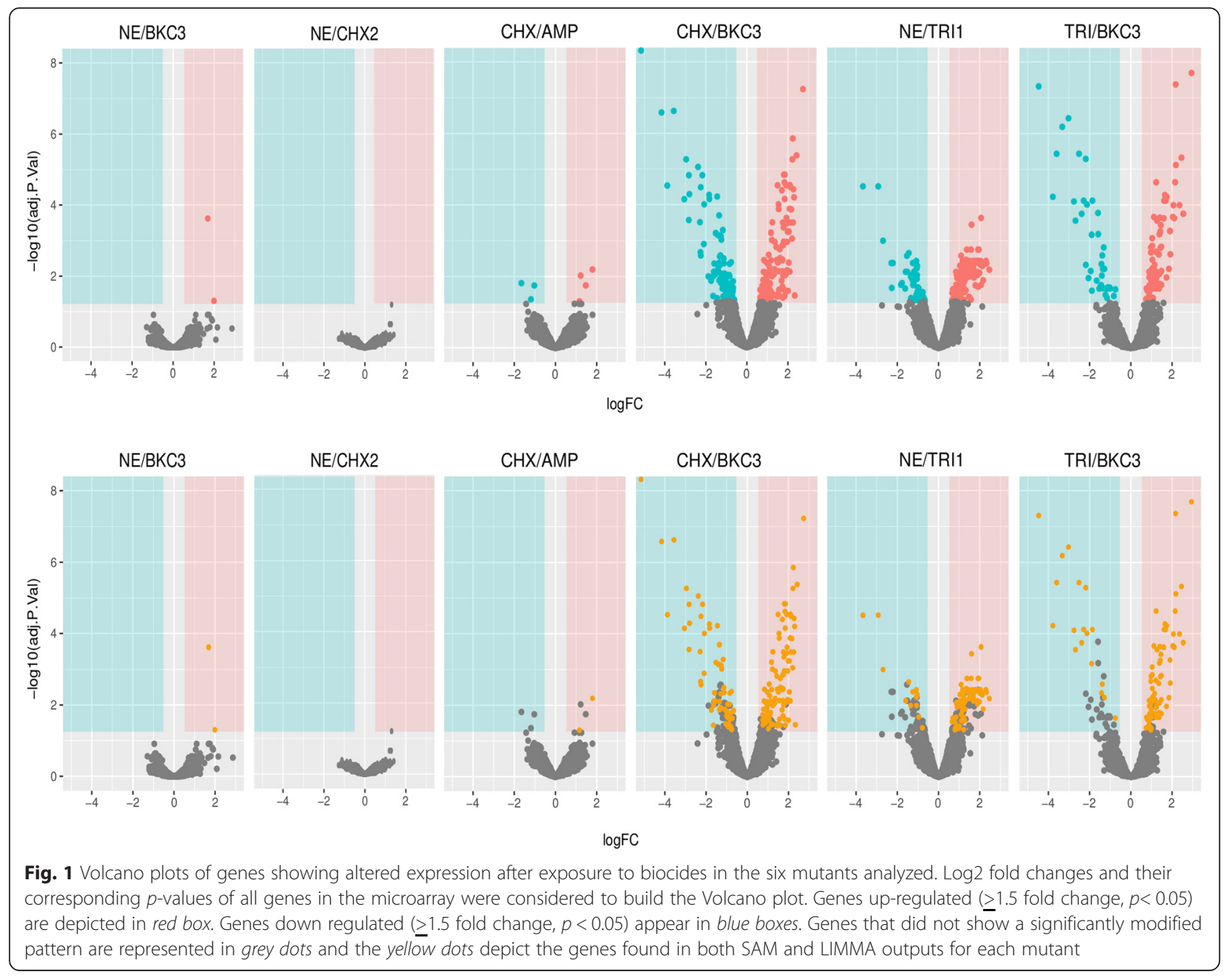

as some within type III secretion system complex, e.g. prgI, $p g r H$ and sopE or possibly ompC, encoding surface proteins involved in chemotaxis signal transduction system i.e. part of flagella and invasion proteins (iagB and $\operatorname{org} A$ ). The resultant proteins regulate the events that lead to changes in the swimming behaviour of the cell [37]. Moreover, the two mutants NE/TRI1 and CHX/BKC3 distinguished from the rest by the down-expression of genes linked to threonine metabolism $(t d c B$ and $t d c C)$.

Overexpression of genes coding for metabolic enzymes related to energy production such as glucose catabolism (GapA pyruvate kinase, fumarate reductase), some PTS systems and other carbohydrate metabolic components were shown for TRI/BKC3.

Genes with a function related to some of those with mutations such as ftsl2 and ftsH, yeaD, yeaC and yeaF, $t d c B, t d c C$ and $t d c E$ were found to have altered expression in several mutants.
Similar transcriptomic profiles were exhibited by field Salmonella strains showing variable reduced susceptibility to biocides and the laboratory-selected mutants

The genes with altered expression in mutants were investigated for their expression in field isolates with decreased susceptibility to biocides (Fig. 3, Fig. 4 and Additional file 3: Table S2). Over and down expression of particular genes was noticed for both natural isolates and mutants ( 3 and -4 fold changes, respectively).

Similarly to what was observed for mutants, transcriptomic changes did not fully correlate with the phenotypes of susceptibility to biocides. However, enhanced expression of some of the same ribosomal proteins was identified for field strains. A higher number of metabolism-related genes were over-expressed in the wild-type isolates. Furthermore, the over-expression of genes encoding pathogenicity-related proteins (e.g. macrophage stimulating factor, flagellar hook-associated, 


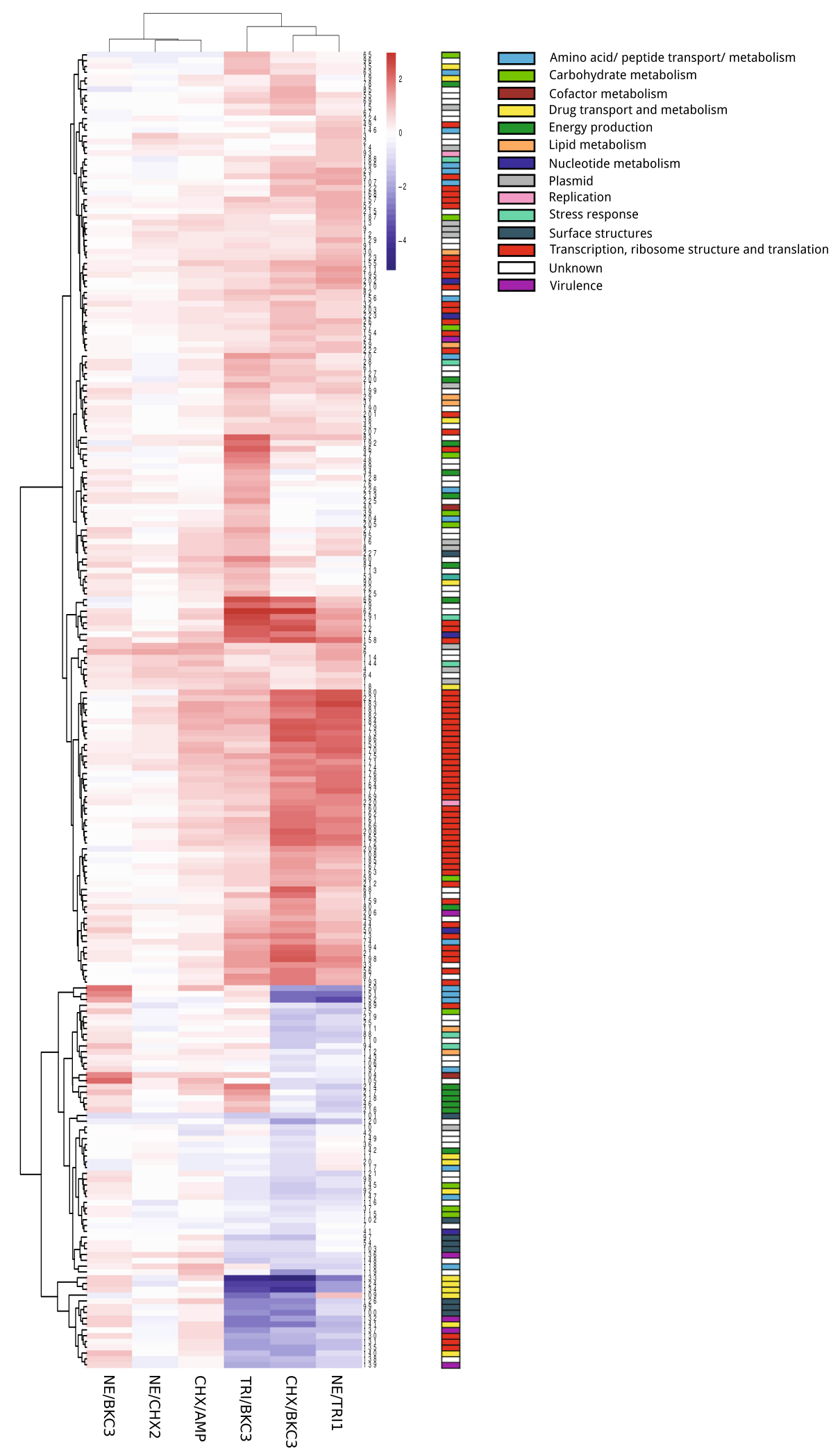

Fig. 2 Heat map of the genes with altered expression in different mutants 


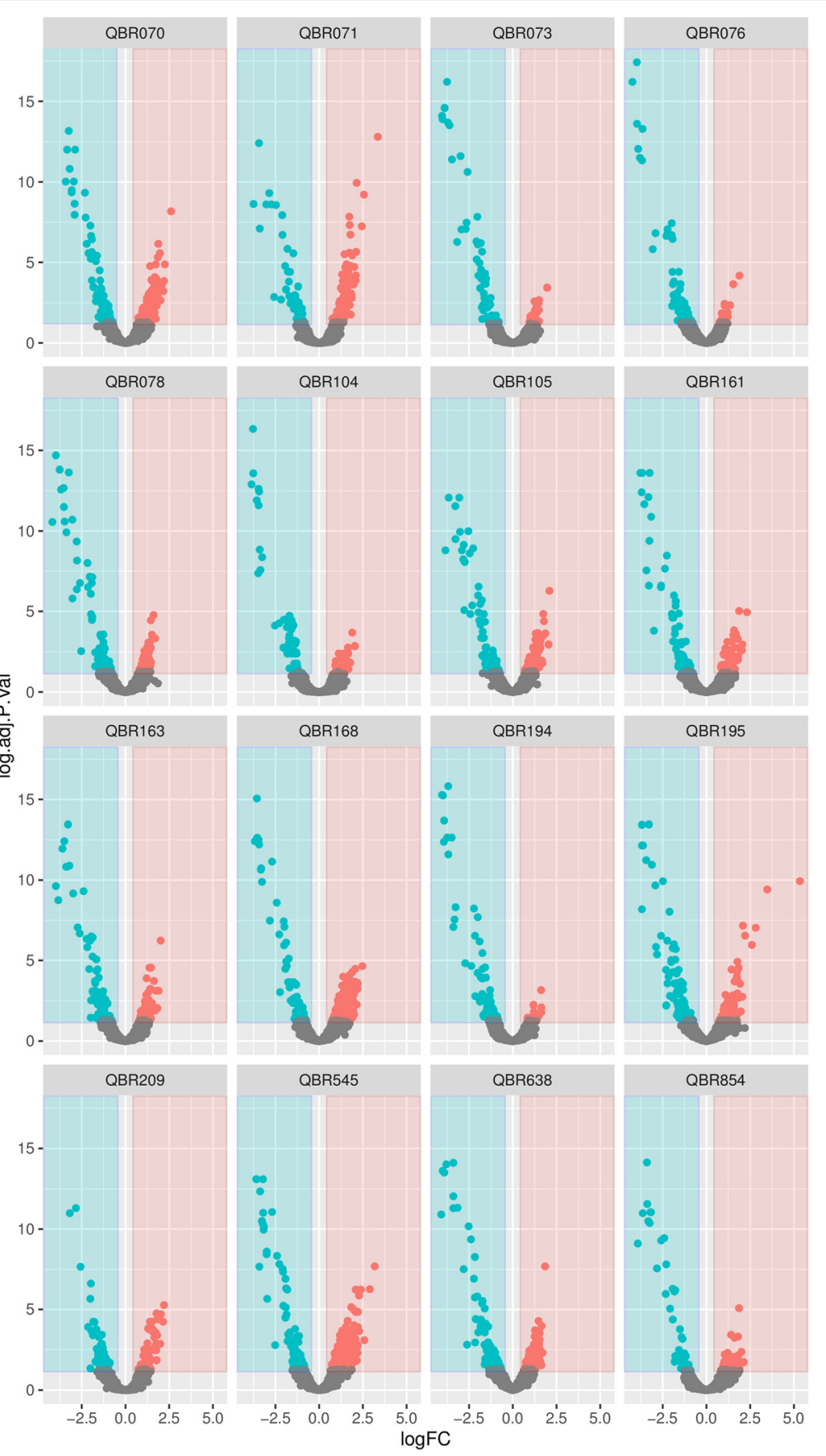

Fig. 3 Volcano plots of genes showing altered expression in both natural isolates and mutants. Log2 fold changes and their corresponding $p$-values of all genes in the microarray were considered to build the Volcano plot. Genes up-regulated $(>1.5$ fold change, $p<0.05)$ are depicted in red box. Genes down regulated $(\geq 1.5$ fold change, $p<0.05)$ appear in blue boxes. Genes that did not show a significantly modified pattern are represented in grey dots.

factor PagK and membrane-related such as PgtE protease) occurred in different strains.

Other changes were only detected among wild-type strains. For example, the strain with the highest MBC for TRI $(>512 \mathrm{mg} / \mathrm{L}$ ) showed a high level expression of the $\mathrm{ABC}$ transporter $y d e Y$, a pump for which a role on biocide resistance has not been described so far. Up-regulation of genes involved in the modification of the lipid A implicated in polymyxin resistance was found for some $\mathrm{TRI}^{\mathrm{R}}$ and $\mathrm{BKC}^{\mathrm{R}}$ strains. On the other hand, slight down-regulation of the acrE efflux pump was observed in three PFGEunrelated strains exhibiting a susceptible biocide phenotype 


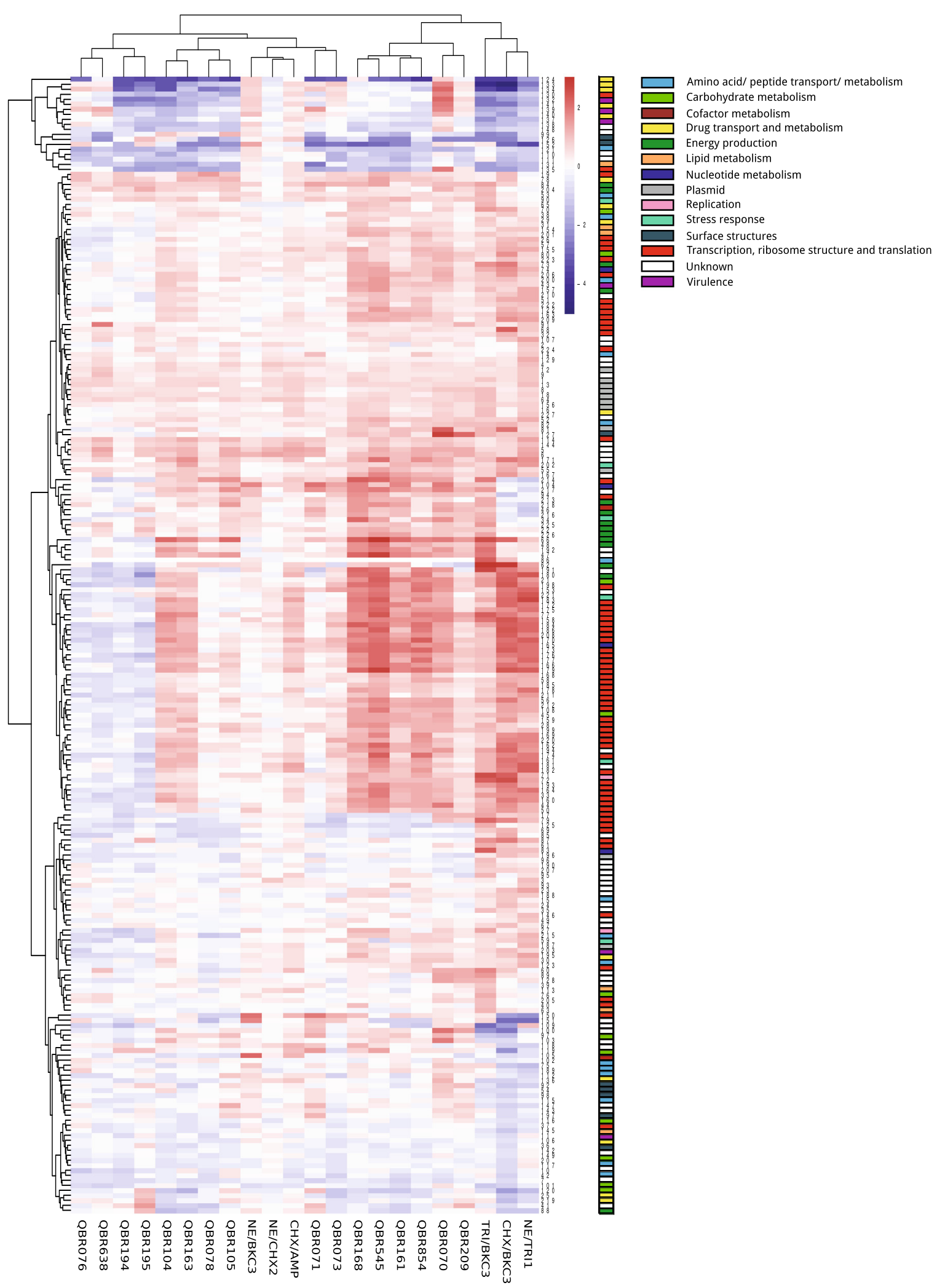

Fig. 4 Heat map of the common genes with altered expression of natural isolates and mutants 
$\left(\mathrm{TRI}^{\mathrm{S}} / \mathrm{CHX}^{\mathrm{S}} / \mathrm{BKC}^{\mathrm{S}}\right)$ while one of them had the sugE gene over-expressed. A number of antibiotic resistance genes were up- or down-regulated in natural isolates.

\section{Resistance to biocides reduces the fitness of Salmonella SL1344}

Variable values of fitness cost (FC) were observed for some mutants with disparate biocide phenotype (Table 1 and Additional file 1: Figure S2). Both NE/CHX2 (TRI ${ }^{\mathrm{R}} /$ $\mathrm{BKC}^{\mathrm{R}} / \mathrm{CHX}^{\mathrm{R}}$ ), which did not show any considerable susceptibility change, and TRI/BKC3 $\left(\mathrm{TRI}^{\mathrm{HS}} / \mathrm{BKC}^{\mathrm{R}} / \mathrm{CHX}^{\mathrm{R}}\right)$, showed the highest $\mathrm{FC}$ values $(34 \%$ and $31 \%$, respectively). They had deleted $b i g A$ gene. Mutants $\mathrm{TRI}^{\mathrm{R}} / \mathrm{BKC}^{\mathrm{R}} /$ $\mathrm{CHX}^{\mathrm{R}}$ (NE/TRI1), and TRI ${ }^{\mathrm{HS}}$ (CHX/AMP) showed similar FC values (11 \% and $16 \%$, respectively) (Additional file 1: Figure S2). Mutants fitter than parental strain showed increased $\mathrm{MIC}_{\mathrm{CAZ}}$.

Besides changes in growth rates, altered colony morphology was also observed. Although several mutants had smoother and smaller colonies than the parental strain, we did not observe notable differences in the rdar (red, dry and rough) morphotype, an aggregative and resistant physiological state which has been linked to survival in nutrient-limited environments [38], or in the genomic XbaI-genomic digested DNA profiles (Additional file 1: Figure S3).

\section{Discussion}

This paper documents a versatile adaptive response of the Salmonella enterica strain SL1344 after exposure to inhibitory concentrations of biocides or antibiotics which resulted on a diversity of phenotypes and genomic and proteomic changes. The emergence of mutants with phenotypes of antimicrobial resistance (antibiotics and/ or biocides) which had not been previously exposed to antimicrobial agents but were recovered on selection plates, suggests that a variety of mutants with altered susceptibility to biocides easily arises. Biocides, acting on multiple cellular targets, would drive random selection of mutants, eventually causing pleiotropic changes; and therefore a high diversity of phenotypes were associated with biocide-tolerance. The fact that SHC did not select for mutants might provide a chance for efficient and safe sanitization.

Most mutants showed slight variations in their MIC values to the antimicrobials tested. Although crossresistance between biocides and antibiotics is frequently described for biocide resistant mutants, we also observed increased susceptibility for some antimicrobials, a phenomenum that can be attributed to frequent collateral effects in the emergence of resistance as previously documented for antibiotic resistant bacteria [39, 40]. Indeed, antimicrobial resistant mutants of Salmonella presented increased susceptibility to envelope active inhibitory compounds. Importantly, this sort of compounds turns the cytoplasmic membrane more permeable, which often results on reduced viability. Therefore the ability to become resistant to these antimicrobials is lower. A part from the membrane vulnerability, most mutants potentially had alterations in the oxidative metabolism and protein synthesis. Our data showed that TRI resistance was often accompanied by higher tolerance to compounds of different antibiotic families, with the exception of aminoglycosides. This finding is in line with other studies in Salmonella enterica strains that reported increases in the susceptibility to aminoglycosides and CHX accompanying TRI ${ }^{\mathrm{R}}[41,42]$. While most studies on the field focused on the analysis of cross-resistance of biocides and antibiotics, negative epistasis phenomena inferred from the simultaneous emergence of susceptibility to aminoglycosides or biocides and resistance to other antimicrobial agents are not uncommon [20,39]. This antagonistic pleiotropy epistatic effect known as "collateral sensitivity" must be taken into consideration when evaluating the risks for the acquisition of resistance or to envisage methods for reducing or even eliminating resistant microorganisms in the field [40, 43].

Comparative genomic analysis revealed changes in a variety of genes, some of them previously linked to tolerance to antibiotics or metals (fabI, yea and fts) [44] and others newly identified here. Different amino acid changes at position 93 of the FabI protein resulted in TRI $^{R}$ phenotypes [24, 32, 41, this study]. However, differences in the polarity of amino acids at position 93 might be associated with distinct structural conformations of FabI protein that would affect $\mathrm{MIC}_{\mathrm{TRI}}$ values; higher values $\left(\mathrm{MIC}_{\mathrm{TRI}} \geq 2 \mathrm{mg} / \mathrm{L}\right.$ for the mutant of this study) occurring when an uncharged amino acid (Gly or Val) is substituted by a polar amino acid (Ser).

Non-functional ftsK gene mutants have previously shown increased susceptibility to $\beta$-lactams and CIP and tolerance to chromate in Pseudomonas aeruginosa [45]. In this study mutants with SNPs in ftsK (NE/TRI1 and $\mathrm{CHX} / \mathrm{BKC} 3)$ showed either increased susceptibility to several $\beta$-lactams or to most CIP-related antibiotics, respectively. The tolA gene showed a mutation and differential expression in different mutants. Other SNPs may also modulate virulence in the mutants as for instance, mutants in $m o t B$ (and $m o t A$ ) genes may paralyse the flagellar phenotype influencing adhesion and invasion of cells [46]. Flagellar assembly and/or mobility may antagonize the T3SS that delivers effectors into the host cell of some pathogens, revealing the potential impact of cross talk between some virulence factors depending on the bacterial colonization phase and infection type [47].

While particular changes at genetic level in the mutants were detected, a remarkable alteration of the expression profiles was noted in both mutants and field 
isolates, with overexpression of ribosomal protein synthesis as well the down-regulation of genes involved in global stress and regulatory mechanisms, metabolism of amino acids (lysine, asparagine, threonine), secondary metabolism, transport, virulence, chemotaxis, invasion pathways and of unknown function. This might indicate a higher cellular activity with lower virulence. Efflux pumps previously involved in biocide tolerance were upregulated in some mutants and field isolates. They included SugE, classically implicated in QACs resistance and frequently found in Salmonella isolates of clinical and animal origin $[48,49]$ or AcrAB [41, 50], whose over-expression is known to contribute to antimicrobial resistance yet at low-level.

This is the first study characterizing both the genomic and expression profiles after antimicrobials challenge, although the stress response after exposure to a high diversity of environmental stressors including biocides or antibiotics has been tackled before. Cold-shock response, allowing the survival of Listeria monocutogenes in the presence of biocides was previously reported [10]. Similarly to the mutants selected in BKC in this study, antibiotic-resistant mutants obtained under different metabolic conditions were related to attenuated virulence due to low expression of the T3SS [51-53], or mutation in transcriptional regulators. The RNA polymerase regulates the transcription of genes encoding transport proteins and enzymes involved in the biosynthesis of the metabolic intermediates of exopolysaccharides, lipids, lipopolysaccharides, lipoproteins, flagella and peptidoglycan. This protein is stress-induced and plays a central role in the control of processes that involve physical interaction of an organism with the environment, as colonization of host surfaces (virulence) or biofilm formation [54]. Polymorphisms in genes coding for RNA polymerase subunit $\alpha$ (rpoA, described in mutants selected in QACs) [24, 50], and also $\sigma$ factors (rpoS and $r p o D$ genes, related to high-level resistance towards TRI) [55]) were previously reported. Despite other genes coding for RNA polymerase activity $(r p o Z$ and $r p o B)$ were shown here to be up-regulated, it corroborates the importance of this protein as a target implicated in intrinsic resistance to biocides [23, 55]. Conversely, downregulation of transcriptional and ribosomal genes were previously detected after exposure to CHX [50]. In addition, we report less transcripts of members of the LuxR/UhpA and AraC family, the last one being negative regulator of HilA, the key regulator of the SPI1 $[35,36]$. Down-regulation of genes encoding virulencerelated proteins for several mutants might suggest a lower pathogenicity.

The finding of similar transcriptomic changes found in both biocide resistant mutants and field isolates with reduced susceptibility to biocides, suggests the involvement of common general responses that include diverse alterations in metabolic and chemotaxis pathways, protein synthesis, cell envelope or regulation of pathogenicity-islands, which has been reported in other studies analysing biocide-induced mutants of Salmonella and other species $[9,19,56]$.

\section{Conclusions}

In summary, this study shows that growth of Salmonella in the presence of selective concentrations of biocides or antibiotics leads to the selection of mutants with variable susceptibility to antimicrobials ("cross-resistance" or "collateral sensitivity"-like phenotypes) which is consistent with the "multiples target sites" hypothesis of most biocidal agents $[57,58]$. The results highlight the wide range of pathways employed by Salmonella to counteract biocides and achieve stasis/stress survival. Unlike to what has been commonly reported, overexpression of AcrAB-like pumps did not seem to be the main mechanism involved in biocide tolerance. Detection of SNPs was not associated with altered expression of related genes, making data from genomic and transcriptomic analysis necessary for a comprehensive analysis of biocide-challenged strains. Finally, most selected biocide-resistant mutants presented fitness costs, an issue that might reduce their chances to spread under non-selective conditions.

\section{Additional files}

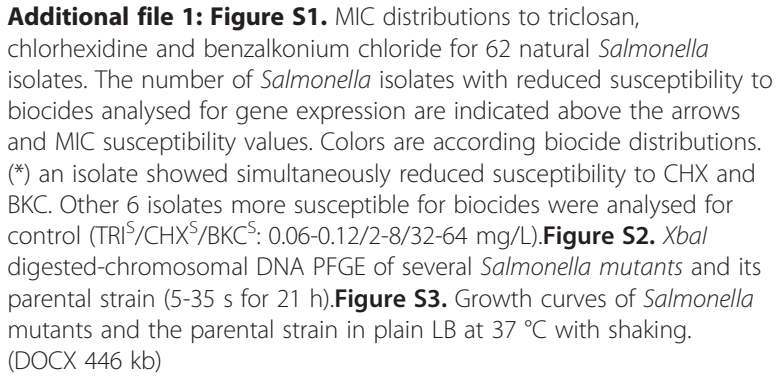

Additional file 1: Figure S1. MIC distributions to triclosan, chlorhexidine and benzalkonium chloride for 62 natural Salmonella isolates. The number of Salmonella isolates with reduced susceptibility to biocides analysed for gene expression are indicated above the arrows and MIC susceptibility values. Colors are according biocide distributions.

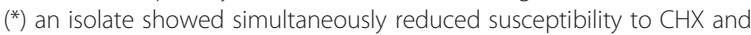
BKC. Other 6 isolates more susceptible for biocides were analysed for control ( $\mathrm{TRI}^{\mathrm{S}} / \mathrm{CHX}^{\mathrm{S}} / \mathrm{BKC}^{\mathrm{S}}$ : 0.06-0.12/2-8/32-64 mg/L).Figure S2. Xbal digested-chromosomal DNA PFGE of several Salmonella mutants and its parental strain (5-35 s for 21 h).Figure S3. Growth curves of Salmonella mutants and the parental strain in plain LB at $37{ }^{\circ} \mathrm{C}$ with shaking. (DOCX $446 \mathrm{~kb})$

Additional file 2: Table S1. Differential gene expression of common genes from LIMMA and SAM methods for mutants. (XLSX $48 \mathrm{~kb}$ )

Additional file 3: Table S2. Differential gene expression of common genes from LIMMA and SAM methods for natural isolates. (XLSX $280 \mathrm{~kb}$ )

\footnotetext{
Acknowledgements

During the execution of this study, T.C. was recipient of a predoctoral fellowship from Instituto Carlos III (PFIS-FI09/00901) and R.L.S. was financed by a contract-associated project (PI12-01581). We acknowledge the European Development Regional Fund "A way to achieve Europe" (ERDF), and for cofounding the Plan Nacional de I + D+ I 2012-2015 (PI12-01581) and CIBER actions (CIBER in Epidemiology and Public Health, CIBERESP; CB06/02/0053). We are also grateful to the anonymous reviewers for their critical input that contributed to significantly improve the manuscript, and also to Val F. Lanza for his helpful advice in using " $\mathrm{R}$ " and some tools for bioinformatic analysis of genome sequencing data.
} 


\section{Funding}

This study was supported by funds from the European Commission (KBBE2008-2B-227258-BIOHYPO to D.G., C.V., M.R.O., and J.L.M.); the Ministry of Economy and Competitiveness of Spain [grant BIO2014-54507-R to J.L.M., grant PI12-01581 to T.M.C., the CIBERESP Network for Biomedical Research in Epidemiology and Public Health (CB06/02/0053) to F.B. and T.M.C., the Spanish Network for Research on Infectious Diseases (REIPI RD12/0015) from the Instituto de Salud Carlos III to J.L.M.] and the Regional Government of Madrid-CAM (S2010/BMD2414-PROMPT) to J.L.M. and F.B.

\section{Availability of data and materials}

All relevant data are available within the manuscript and its additional files.

\section{Authors' contributions}

T.C., D.G. C.V., M.R.O., J.L.M. and T.M.C. contributed to the study design. T.C. performed the experimental work related to the selection and characterization of biocide mutants, participated in the analysis of phenotypic data, genomic and transcriptomics, and wrote the manuscript. E.M. and C.V. performed the analysis with Phenotypic Microarrays (Biolog). D.G. developed the expression microarrays, and participated in the data analysis. R.L.S. performed the bioinformatics analysis of data from genome sequencing and microarrays and participated in the revision of the manuscript. S.L.L. participated in the development of the expression microarrays and in related data analysis. F.B. and M.R.O. provided expertise, participated in the analysis of data, and the revision of the manuscript. J.L.M. and T.M.C. participated in the analysis of data, and wrote the manuscript. All authors read and approved the final version of this manuscript.

\section{Competing interests}

The authors declare that they have no competing interests.

\section{Ethics approval and consent to participate}

Not applicable.

\begin{abstract}
Author details
${ }^{1}$ Servicio de Microbiología, Instituto Ramón y Cajal de Investigación Sanitaria (IRYCIS), Madrid, Spain. ${ }^{2}$ CIBER Epidemiología y Salud Pública (CIBERESP), Madrid, Spain. ${ }^{3}$ Unidad de Resistencia a Antibióticos y Virulencia bacteriana asociada al Consejo Superior de Investigaciones Científicas (CSIC), Madrid, Spain. ${ }^{4}$ Department of Agrifood Production and Environmental Sciences, University of Florence, Firenze, Italy. ${ }^{5}$ Neuroinfection Laboratory, Institute for Infectious Diseases, Bern, Switzerland. 'University of Leicester, Leicester, UK. ${ }^{7}$ Departamento de Biotecnología Microbiana, Centro Nacional de Biotecnología (CSIC), Darwin 3, Cantoblanco, Madrid 28049, Spain.
\end{abstract}

Received: 16 October 2015 Accepted: 26 May 2016 Published online: 13 July 2016

\section{References}

1. Parry CM, Threlfall EJ. Antimicrobial resistance in typhoidal and nontyphoidal salmonellae. Curr Opin Infect Dis. 2008;21:531-8.

2. Barat $S$, Steeb B, Mazé $A$, Bumann D. Extensive in vivo resilience of persistent Salmonella. PLoS One. 2012;7:e42007.

3. Condell O, Iversen C, Cooney S, Power KA, Walsh C, Burgess C, Fanning S. Efficacy of biocides used in the modern food industry to control Salmonella enterica, and links between biocide tolerance and resistance to clinically relevant antimicrobial compounds. Appl Environ Microbiol. 2012;78:3087-97.

4. Beier RC, Anderson PN, Hume ME, Poole TL, Duke SE, Crippen TL, Sheffield CL, Caldwell DJ, Byrd JA, Anderson RC, Nisbet DJ. Characterization of Salmonella enterica Isolates from Turkeys in Commercial Processing Plants for Resistance to Antibiotics, Disinfectants, and a Growth Promoter. Foodborne Pathog Dis. 2011:8:593-600.

5. Whitehead RN, Overton TW, Kemp CL, Webber MA. Exposure of Salmonella enterica Serovar Typhimurium to High Level Biocide Challenge Can Select Multidrug Resistant Mutants in a Single Step. PLoS One. 2011;6:e22833.

6. Randall LP, Cooles SW, Coldham NG, Penuela EG, Mott AC, Woodward MJ, Piddock LJV, Webber MA. Commonly used farm disinfectants can select for mutant Salmonella enterica serovar Typhimurium with decreased susceptibility to biocides and antibiotics without compromising virulence. J Antimicrob Chemother. 2007;60(September):1273-80.
7. Piddock LV. Clinically Relevant Chromosomally Encoded Multidrug Resistance Efflux Pumps in Bacteria Clinically Relevant Chromosomally Encoded Multidrug Resistance Efflux Pumps in Bacteria. Clin Microbiol Rev. 2006;19:382-402.

8. Bialek-davenet S, Marcon E, Lavigne J, Moreau R: In Vitro Selection of ramR and soxR Mutants Overexpressing Efflux Systems by Fluoroquinolones as Well as Cefoxitin in Klebsiella pneumoniae. Antimicrob Agents Chemother. 2011;55:2795-2802

9. Bailey AM, Constantinidou C, Ivens A, Garvey MI, Webber MA, Coldham N, Hobman JL, Wain J, Woodward MJ, Piddock LJV. Exposure of Escherichia coli and Salmonella enterica serovar Typhimurium to triclosan induces a speciesspecific response, including drug detoxification. J Antimicrob Chemother. 2009;64(September):973-85.

10. Fox EM, Leonard N, Jordan K. Physiological and transcriptional characterization of persistent and nonpersistent Listeria monocytogenes isolates. Appl Environ Microbiol. 2011;77:6559-69.

11. Bore E, Hébraud M, Chafsey I, Chambon C, Skjaeret C, Moen B, Møretrø T, Langsrud $\varnothing$, Rudi K, Langsrud S. Adapted tolerance to benzalkonium chloride in Escherichia coli K-12 studied by transcriptome and proteome analyses. Microbiology. 2007;153(Pt 4):935-46.

12. Condell O, Sheridan Á, Power KA, Bonilla-Santiago R, Sergeant K, Renaut J, Burgess C, Fanning S, Nally JE. Comparative proteomic analysis of Salmonella tolerance to the biocide active agent triclosan. J Proteomics. 2012;75:4505-19.

13. Sheridan Á, Lenahan M, Condell O, Bonilla-Santiago R, Sergeant K, Renaut J, Duffy G, Fanning S, Nally JE, Burgess CM. Proteomic and phenotypic analysis of triclosan tolerant verocytotoxigenic Escherichia coli 0157:H19. J Proteomics. 2013;80:78-90

14. McMurry LM, Oethinger M, Levy SB. Triclosan targets lipid synthesis. Nature. 1998;394:531-2.

15. Karatzas KAG, Webber MA, Jorgensen F, Woodward MJ, Piddock LJV, Humphrey TJ. Prolonged treatment of Salmonella enterica serovar Typhimurium with commercial disinfectants selects for multiple antibiotic resistance, increased efflux and reduced invasiveness. J Antimicrob Chemother. 2007:60(September):947-55.

16. Cheung H, Wong MM, Cheung S, Liang LY, Lam Y, Chiu S. Differential Actions of Chlorhexidine on the Cell Wall of Bacillus subtilis and Escherichia coli. PLoS One. 2012;7:e36659.

17. Bailey AM, Ivens A, Kingsley R, Cottell JL, Wain J, Piddock LJV. RamA, a member of the AraC/XylS family, influences both virulence and efflux in Salmonella enterica serovar Typhimurium. J Bacteriol. 2010;192:1607-16.

18. Mark A. Webber, Andrew M. Bailey, Jessica M. A. Blair, Eirwen Morgan, Mark P. Stevens, Jay C. D. Hinton, Al Ivens, John Wain, Piddock L. The Global Consequence of Disruption of the AcrAB-TolC Efflux Pump in Salmonella enterica Includes Reduced Expression of SPI-1 and Other Attributes Required To Infect the Host. J Bacteriol. 2009;191:4276-85.

19. Kastbjerg VG, Larsen $M H, G$ Gram L, Ingmer H. Influence of sublethal concentrations of common disinfectants on expression of virulence genes in Listeria monocytogenes. Appl Environ Microbiol. 2010;76:303-9.

20. Curiao T, Marchi E, Viti C, Oggioni MR, Baquero F, Martinez JL, Coque TM. Polymorphic Variation in Susceptibility and Metabolism of TriclosanResistant Mutants of Escherichia coli and Klebsiella pneumoniae Clinical Strains Obtained after Exposure to Biocides and Antibiotics. Antimicrob Agents Chemother. 2015;59:3413-23.

21. Webber MA, Randall LP, Cooles S, Woodward MJ, Piddock LJV. Triclosan resistance in Salmonella enterica serovar Typhimurium. J Antimicrob Chemother. 2008;62:83-91.

22. Karatzas KAG, Randall LP, Webber M, Piddock LV, Humphrey TJ, Woodward MJ, Coldham NG. Phenotypic and Proteomic Characterization of Multiply AntibioticResistant Variants of Salmonella enterica Serovar Typhimurium Selected Following Exposure to Disinfectants †. Appl Environ Microbiol. 2008;74:1508-16.

23. Mangalappalli-Illathu AK, Korber DR. Adaptive resistance and differential protein expression of Salmonella enterica serovar Enteritidis biofilms exposed to benzalkonium chloride. Antimicrob Agents Chemother. 2006;50: 3588-96.

24. Webber MA, Whitehead RN, Mount M, Loman NJ, Pallen MJ, Piddock LJV. Parallel evolutionary pathways to antibiotic resistance selected by biocide exposure. J Antimicrob Chemother. 2015;70(8):2241-8.

25. Wray CSW. Experimental Salmonella typhimurium infection in calves. Res Vet Sci. 1978;25:139-43.

26. Morrissey I, Oggioni MR, Knight D, Curiao T, Coque T, Kalkanci A, Martinez JL. Evaluation of epidemiological cut-off values indicates that biocide 
resistant subpopulations are uncommon in natural isolates of clinicallyrelevant microorganisms. PLoS One. 2014;9:e86669.

27. Curiao T, Cantón R, Garcillán-Barcia MP, de la Cruz F, Baquero F, Coque TM. Association of composite IS26-sul3 elements with highly transmissible Incl1 plasmids in extended-spectrum-beta-lactamase-producing Escherichia coli clones from humans. Antimicrob Agents Chemother. 2011;55:2451-7.

28. Bochner BR, Gadzinski P, Panomitros E. Phenotype microarrays for highthroughput phenotypic testing and assay of gene function. Genome Res. 2001;11:1246-55.

29. Foucault ML, Depardieu F, Courvalin P, Grillot-Courvalin C. Inducible expression eliminates the fitness cost of vancomycin resistance in enterococci. Proc Natl Acad Sci U S A. 2010;107:16964-9.

30. Hall BG, Acar H, Nandipati A, Barlow M. Growth rates made easy. Mol Biol Evol. 2014;31:232-8.

31. Shintre MS, Gaonkar TA, Modak SM. Efficacy of an alcohol-based healthcare hand rub containing synergistic combination of farnesol and benzethonium chloride. Int J Hyg Environ Health. 2006;209:477-87.

32. Li H, Zhang D-F, Lin X-M, Peng X-X. Outer membrane proteomics of kanamycin-resistant Escherichia coli identified MipA as a novel antibiotic resistance-related protein. FEMS Microbiol Lett. 2015;362(11) fnv074; doi: 10. 1093/femsle/fnv074

33. Levengood-Freyermuth SK, Click EM, Webster RE. Role of the carboxylterminal domain of TolA in protein import and integrity of the outer membrane. J Bacteriol. 1993;175:222-8.

34. Czibener C, Merwaiss F, Guaimas F, Del Giudice MG, Serantes DAR, Spera $\mathrm{JM}$, Ugalde JE. BigA is a novel adhesin of Brucella that mediates adhesion to epithelial cells. Cell Microbiol. 2015;18:500-13.

35. Takaya A, Kubota Y, Isogai E, Yamamoto T. Degradation of the HilC and HilD regulator proteins by ATP-dependent Lon protease leads to downregulation of Salmonella pathogenicity island 1 gene expression. Mol Microbiol. 2005; 55:839-52.

36. Saini S, Rao CV. SprB is the molecular link between Salmonella pathogenicity island 1 (SPI1) and SPI4. J Bacteriol. 2010;192:2459-62.

37. McEvoy MM, Bren A, Eisenbach M, Dahlquist FW. Identification of the binding interfaces on CheY for two of its targets, the phosphatase CheZ and the flagellar switch protein fliM. J Mol Biol. 1999;289:1423-33.

38. White AP, Gibson DL, Grassl GA, Kay WW, Finlay BB, Vallance BA, Surette MG. Aggregation via the red, dry, and rough morphotype is not a virulence adaptation in Salmonella enterica serovar Typhimurium. Infect Immun. 2008; 76:1048-58.

39. Lázár V, Pal Singh G, Spohn R, Nagy I, Horváth B, Hrtyan M, Busa-Fekete R, Bogos B, Méhi O, Csörgő B, Pósfai G, Fekete G, Szappanos B, Kégl B, Papp B, Pál C. Bacterial evolution of antibiotic hypersensitivity. Mol Syst Biol. 2013;9: 700.

40. Pal C, Papp B, Lazar V. Collateral sensitivity of antibiotic-resistant microbes. Trends Microbiol. 2015;23:401-7.

41. Rensch U, Klein G, Kehrenberg C. Analysis of Triclosan-Selected Salmonella enterica Mutants of Eight Serovars Revealed Increased Aminoglycoside Susceptibility and Reduced Growth Rates. PLoS One. 2013;8:e78310.

42. Cottell A, Denyer SP, Hanlon GW, Ochs D, Maillard J-Y. Triclosan-tolerant bacteria: changes in susceptibility to antibiotics. J Hosp Infect. 2009;72:71-6.

43. Baquero F, Lanza VF, Cantón R, Coque TM. Public health evolutionary biology of antimicrobial resistance: priorities for intervention. Evol Appl. 2015;8:223-39

44. Yu BJ, Kim JA, Ju HM, Choi S-K, Hwang SJ, Park S, Kim E, Pan J-G. Genomewide enrichment screening reveals multiple targets and resistance genes for triclosan in Escherichia coli. J Microbiol. 2012;50:785-91.

45. Alvarez-Ortega C, Wiegand I, Olivares J, Hancock REW, Martínez JL. Genetic determinants involved in the susceptibility of Pseudomonas aeruginosa to beta-lactam antibiotics. Antimicrob Agents Chemother. 2010;54:4159-67.

46. Achouri S, Wright JA, Evans L, Macleod C, Fraser G, Cicuta P, Bryant CE. The frequency and duration of Salmonella - macrophage adhesion events determines infection efficiency. Philos Transl B. 2015;370:20140033.

47. Soscia C, Hachani A, Bernadac A, Filloux A, Bleves S. Cross talk between type III secretion and flagellar assembly systems in Pseudomonas aeruginosa. J Bacteriol. 2007:189:3124-32.

48. Zou L, Meng J, McDermott PF, Wang F, Yang Q, Cao G, Hoffmann M, Zhao S. Presence of disinfectant resistance genes in Escherichia coli isolated from retail meats in the USA. J Antimicrob Chemother. 2014;69:2644-9.
49. Su LH, Chen HL, Chia JH, Liu SY, Chu C, Wu TL, Chiu CH. Distribution of a transposon-like element carrying blacmy-2 among Salmonella and other Enterobacteriaceae. J Antimicrob Chemother. 2006;57:424-9.

50. Condell O, Power KA, Händler K, Finn S, Sheridan A, Sergeant K, Renaut J, Burgess CM, Hinton JCD, Nally JE, Fanning $S$. Comparative analysis of Salmonella susceptibility and tolerance to the biocide chlorhexidine identifies a complex cellular defense network. Front Microbiol. 2014;5:373.

51. Giraud E, Baucheron S, Virlogeux-Payant I, Nishino K, Cloeckaert A. Effects of natural mutations in the ramRA locus on invasiveness of epidemic fluoroquinolone-resistant Salmonella enterica serovar Typhimurium isolates. J Infect Dis. 2013:207:794-802.

52. Golubeva YA, Sadik AY, Ellermeier JR, Slauch JM. Integrating global regulatory input into the Salmonella pathogenicity island 1 type III secretion system. Genetics. 2012;190:79-90.

53. Linares JF, López JA, Camafeita E, Albar JP, Rojo F, Martínez JL. Overexpression of the multidrug efflux pumps MexCD-OprJ and MexEFOprN is associated with a reduction of type III secretion in Pseudomonas aeruginosa. J Bacteriol. 2005;187:1384-91.

54. Francke C, Groot Kormelink T, Hagemeijer Y, Overmars L, Sluijter V, Moezelaar R, Siezen RJ. Comparative analyses imply that the enigmatic Sigma factor 54 is a central controller of the bacterial exterior. BMC Genomics. 2011;12:385.

55. Gantzhorn MR, Olsen JE, Thomsen LE. Importance of sigma factor mutations in increased triclosan resistance in Salmonella Typhimurium. BMC Microbiol. 2015;15:105

56. Casey A, Fox EM, Schmitz-Esser S, Coffey A, McAuliffe O, Jordan K. Transcriptome analysis of Listeria monocytogenes exposed to biocide stress reveals a multi-system response involving cell wall synthesis, sugar uptake, and motility. Front Microbiol. 2014;5:1-10.

57. Russell AD. Mechanisms of antimicrobial action of antiseptics and disinfectants: an increasingly important area of investigation. J Antimicrob Chemother. 2002;49:597-9.

58. Maillard J-Y. Bacterial target sites for biocide action. J Appl Microbiol. 2002; 92(Suppl):16S-27S.

\section{Submit your next manuscript to BioMed Central and we will help you at every step:}

- We accept pre-submission inquiries

- Our selector tool helps you to find the most relevant journal

- We provide round the clock customer support

- Convenient online submission

- Thorough peer review

- Inclusion in PubMed and all major indexing services

- Maximum visibility for your research

Submit your manuscript at www.biomedcentral.com/submit 